\title{
ORIGINAL ARTICLE \\ Population divergence and gene flow in an endangered and highly mobile seabird
}

\author{
AJ Welch ${ }^{1,2,11}$, RC Fleischer ${ }^{1,2}$, HF James ${ }^{3}$, AE Wiley ${ }^{3,4}$, PH Ostrom ${ }^{4}$, J Adams ${ }^{5}$, F Duvall ${ }^{6}$, N Holmes ${ }^{7,12}$, \\ $\mathrm{D} \mathrm{Hu}^{8}, \mathrm{~J}$ Penniman ${ }^{9}$ and KA Swindle ${ }^{10}$
}

Seabirds are highly vagile and can disperse up to thousands of kilometers, making it difficult to identify the factors that promote isolation between populations. The endemic Hawaiian petrel (Pterodroma sandwichensis) is one such species. Today it is endangered, and known to breed only on the islands of Hawaii, Maui, Lanai and Kauai. Historical records indicate that a large population formerly bred on Molokai as well, but this population has recently been extirpated. Given the great dispersal potential of these petrels, it remains unclear if populations are genetically distinct and which factors may contribute to isolation between them. We sampled petrels from across their range, including individuals from the presumably extirpated Molokai population. We sequenced $524 \mathrm{bp}$ of mitochondrial DNA, $741 \mathrm{bp}$ from three nuclear introns, and genotyped 18 microsatellite loci in order to examine the patterns of divergence in this species and to investigate the potential underlying mechanisms. Both mitochondrial and nuclear data sets indicated significant genetic differentiation among all modern populations, but no differentiation was found between historic samples from Molokai and modern birds from Lanai. Populationspecific nonbreeding distribution and strong natal philopatry may reduce gene flow between populations. However, the lack of population structure between extirpated Molokai birds and modern birds on Lanai indicates that there was substantial gene flow between these populations and that petrels may be able to overcome barriers to dispersal prior to complete extirpation. Hawaiian petrel populations could be considered distinct management units, however, the dwindling population on Hawaii may require translocation to prevent extirpation in the near future.

Heredity (2012) 109, 19-28; doi:10.1038/hdy.2012.7; published online 21 March 2012

Keywords: Cytochrome b; intron; microsatellite; population; Hawaiian petrel; Pterodroma sandwichensis

\section{INTRODUCTION}

Populations are fundamental units in evolutionary biology and exist in a balance between genetic isolation and gene flow (Allendorf and Luikart, 2007). The mechanisms involved in reducing gene flow and promoting genetic differentiation between populations of highly mobile seabirds, which can travel hundreds to thousands of kilometers during a single foraging trip, can be difficult to identify a priori. Several mechanisms have been hypothesized (Friesen et al., 2007a). Physical barriers, such as the Isthmus of Panama and continental landmasses, can isolate populations in different ocean basins (Steeves et al., 2005). Geographic distance between colonies may also be important and seabirds may preferentially disperse to neighboring colonies over more distant ones (Burg et al., 2003). Strong philopatry may also be an important mechanism. Once seabirds have selected a breeding site, they are known to return there over multiple years to breed (Warham, 1990). These species may also exhibit philpatry to natal sites. Given the widespread and patchy distribution of suitable breeding habitat, birds may return to their natal colony to breed, as they know from experience that a chick can be successfully raised there (Friesen et al., 2007a). However, seabirds may disperse if habitat quality decreases, for example, due to density-dependent factors (Kildaw, 2005). Finally, population-specific nonbreeding or foraging distribution may be important in reducing contact between individuals from different colonies (Burg and Croxall, 2001). The relative importance of these factors remains unclear. It is also unclear if these mechanisms are strong enough to prevent dispersal from colonies at risk of becoming extirpated, for example, due to the introduction of exotic mammalian predators.

Investigating levels of gene flow and the factors promoting genetic differentiation in seabirds has important implications for their conservation. Today, many seabird species, and in some cases nearly entire genera, are threatened by extinction (Gangloff et al., 2011). Information about population genetic differentiation and levels of dispersal can be useful for identifying management units. Such knowledge can also be useful for informing translocation strategies to promote demographic stability, prevent inbreeding and preserve genetic

\footnotetext{
${ }^{1}$ Smithsonian Conservation Biology Institute, Center for Conservation and Evolutionary Genetics, National Zoological Park, Washington, DC, USA; ${ }^{B}$ Behavior, Ecology, Evolution and Systematics Program, University of Maryland, College Park, MD, USA; ${ }^{3}$ Department of Vertebrate Zoology, National Museum of Natural History, Smithsonian Institution,

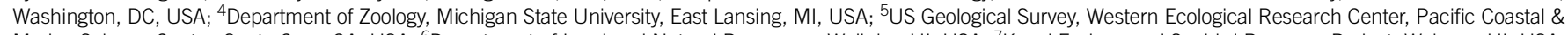
Marine Science Center, Santa Cruz, CA, USA; ${ }^{6}$ Department of Land and Natural Resources, Wailuku, HI, USA; ${ }^{7}$ Kauai Endangered Seabird Recovery Project, Waimea, HI, USA; ${ }^{8}$ National Park Service, Pacific West Regional Office, Honolulu, HI, USA; ${ }^{9}$ Pacific Cooperative Studies Unit, University of Hawaii, Honolulu, HI, USA and 10 US Fish and Wildlife Service, Office of Law Enforcement, Honolulu, HI, USA.

${ }^{11}$ Current address: Department of Biological Sciences, University at Buffalo, 109 Cooke Hall, Buffalo, NY 14260, USA.

${ }^{12}$ Current address: Island Conservation; Center for Ocean Health, 100 Shaffer Road, Santa Cruz, CA 95060, USA.

Correspondence: Dr AJ Welch, Department of Biological Sciences, University at Buffalo, 109 Cooke Hall, Buffalo, NY 14260, USA.

E-mail: andreann@buffalo.edu
}

Received 27 May 2011; revised 26 September 2011; accepted 6 December 2011; published online 21 March 2012 
diversity (Frankham et al., 2002). Preventing the further decline of seabird populations is important because these species have broad ecological impacts. As marine predators, seabirds have an essential role in transferring marine nutrients to terrestrial ecosystems on oceanic islands, and therefore they can influence ecosystem productivity at multiple levels (Croll et al., 2005; Fukami et al., 2006).

The Hawaiian petrel (Pterodroma sandwichensis) is a highly mobile, endangered, pelagic seabird (Simons and Hodges, 1998; Pyle and Pyle, 2009). It is known to make foraging trips in excess of $10000 \mathrm{~km}$ during the breeding season, ranging from the equator to the Aleutian Islands (Spear et al., 1995; Simons and Hodges, 1998; Adams and Flora, 2010). The Hawaiian petrel is currently known to breed on the islands of Hawaii, Maui, Lanai and Kauai; however, the population on Hawaii appears to be declining at a severe rate and is at risk for extirpation ( $\mathrm{Hu}$ et al., 2001). On the basis of subfossil and historical evidence it is clear that the Hawaiian petrel was much more widespread in the past. Range contractions have occurred on islands with contemporary breeding colonies, and this species appears to have been extirpated completely from Oahu and Molokai (Pyle and Pyle, 2009). Subfossil records indicate that a large population on Oahu may have been extirpated prior to or shortly after European contact in $1778 \mathrm{AD}$ (Olson and James, 1982). Historical records (Munro, 1955) indicate that until recently a large population also bred on the island of Molokai, where petrels were so abundant that they 'darkened the sky' Radar surveys suggest a small number of birds (presumably petrels) visit the island (Pyle and Pyle, 2009), but reports from recent surveys indicate that only five to ten birds have been heard calling, and no burrows or breeding colonies have been located so far (Birdlife International, 2011).

Little information is available about movement among Hawaiian petrel populations. These birds are difficult to study because they spend most of their life at sea and return to land nocturnally to breed in underground burrows. In addition, extant colonies are located at the highest elevations on each island in remote and very rugged terrain (Simons and Hodges, 1998). Banding studies in a colony on Maui have shown that adults are highly philopatric, returning to the same burrow to breed for multiple years (Simons, 1985). However, delayed maturity (these petrels do not begin to breed until $\sim 6$ years of age), coupled with the difficulty of conducting thorough surveys for burrows in rugged terrain, mean that banded chicks have not been resighted (Simons, 1984) and direct evidence of natal philopatry is lacking. Genetic information on dispersal is also limited. Browne et al. (1997) analyzed 13 allozyme loci from blood to study the taxonomy of Galapagos (P. phaeopygia) and Hawaiian petrels. Hawaiian petrels were sampled from a single colony on Maui and all individuals were found to be monomorphic at all loci. Recent evidence from mitochondrial and nuclear DNA sequences obtained from a limited number of individuals indicates that population structure may be present among colonies of these birds on different islands (Welch et al., 2011). However, a more extensive analysis using larger sample sizes and additional population level data, for example, analysis of microsatellite genotypes, is needed.

We have conducted a comprehensive, range-wide population genetic study of the Hawaiian petrel. We obtained samples from all islands where these birds have been known to breed in the past two centuries and developed three genetic data sets, consisting of mitochondrial and nuclear DNA sequences as well as genotypes from 18 microsatellite loci. These data were analyzed to investigate population differentiation and gene flow among all extant populations and a presumably extirpated population from the island Molokai. Furthermore, we discuss the factors promoting population divergence in this highly mobile species.

\section{MATERIALS AND METHODS}

\section{Samples}

A total of 322 Hawaiian petrel samples were obtained from across the current and historical breeding range of this species (Table 1, Figure 1). Modern samples $(N=294)$ consisting of blood, muscle or other tissue, bone and feather were salvaged from carcasses of birds depredated in breeding colonies on Hawaii, Maui, Lanai and Kauai, between 1990 and 2010, or collected from birds that were handled during conservation management procedures, such as rehabilitation following power-line strikes or crashes due to disorientation caused by artificial light sources (Podolsky et al., 1998). Crashed birds and carcasses were assumed to be breeders (or the offspring of breeders) on the island where they were discovered, as nonbreeders depart during the first half of chick-rearing (Simons, 1985; Simons and Hodges, 1998). Blood samples of chicks previously collected from Haleakala National Park, Maui, were also obtained (Browne et al., 1997). Toe pads were sampled from historical Hawaiian petrel museum specimens $(N=28)$, originally collected on Molokai in 1907 and 1914 and deposited at the Bernice P. Bishop and the Los Angeles County Natural History Museums (Supplementary Table 1). It is possible that genetic differentiation could occur among different colonies on the same island (Friesen et al., 2007b), such as between east and west Maui; however, sample sizes are not sufficient to address those questions here, and therefore samples were grouped according to island for all analyses.

\section{Molecular techniques}

Genomic DNA was extracted from blood and tissue samples using the DNEasy tissue kit (Qiagen, Valencia, CA, USA). DNA was obtained from bone, feather and toe pad samples via phenol/chloroform extraction and centrifugal dialysis

Table 1 Sample sizes for Hawaiian petrels ( $P$. sandwichensis) obtained from all islands where this species is currently, or was historically, known to breed

\begin{tabular}{llccc}
\hline \multirow{2}{*}{ Island } & Time period & \multicolumn{3}{c}{ Sample size } \\
\cline { 3 - 5 } & & mtDNA & nuDNA & Micros \\
\cline { 3 - 5 } & & 71 & 51 & 48 \\
Hawaii & Modern & 122 & 54 & 114 \\
Maui & Modern & 38 & 25 & 28 \\
Lanai & Modern & 28 & 0 & 0 \\
Molokai & Historic & 63 & 34 & 42 \\
Kauai & Modern & 322 & 164 & 232 \\
\hline
\end{tabular}

Abbreviations: mtDNA, mitochondrial DNA sequences; nuDNA, nuclear intron DNA sequences.

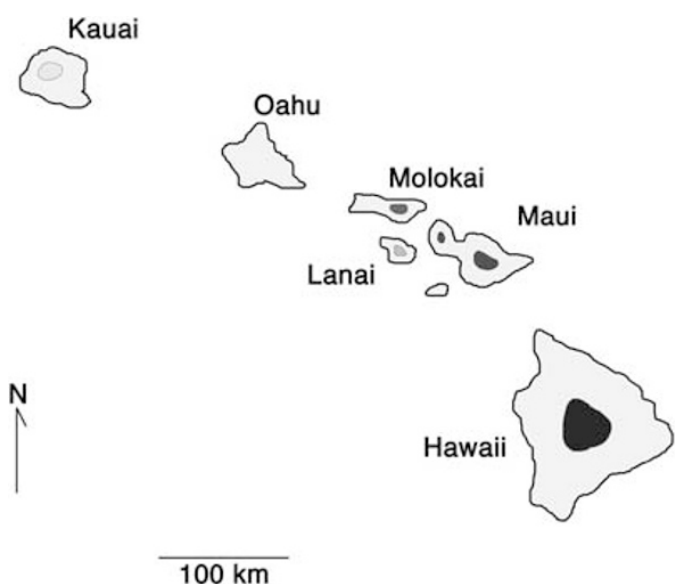

Figure 1 Map of the main Hawaiian Islands with approximate locations of modern (Hawaii, Maui, Lanai and Kauai) and historically known (Molokai) breeding colonies shaded. 
(Fleischer et al., 2000). All extractions for historical samples were performed in a physically separate, dedicated ancient DNA laboratory, and a sample from a different species was extracted in between each Hawaiian petrel sample to detect cross-contamination. Multiple extraction and negative PCR controls were also used to detect contamination.

Three data sets were generated for this study. First, a 524-bp fragment of the mitochondrial Cytochrome $b$ gene was amplified using the primers CytbL and CytbR9 according to Welch et al. (2011). The control region is more variable than Cytochrome b, and often used for population level studies, but this region has been duplicated in procellariiform seabirds (Abbott et al., 2005). To minimize the potential for error and uncertainty, especially in ancient DNA sequences, we utilized the variable $5^{\prime}$ region of the Cytochrome $b$ gene instead. Second, a set of three nuclear intron loci were sequenced, including $\alpha$-Enolase (Enol) intron 8, Lamin A (Lam) intron 3 and Ribosomal Protein 40 (RP40) intron 5 (Friesen et al., 1997, 1999). For both sequence data sets, Primer3 (Rozen and Skaletsky, 2000) was used to design primers to amplify small, overlapping fragments for historic and degraded samples (Supplementary Table 2 ). Third, a set of 18 polymorphic microsatellite loci were amplified (Welch and Fleischer, 2011). For historic samples, a minimum of two independent amplifications were conducted for each mitochondrial and nuclear intron primer set. For microsatellites, loci were amplified and assayed between three and five times per individual for all samples (Taberlet et al., 1996). The genotyping error rate was found to be $0.05 \%$.

Polymerase chain reactions were carried out in $15 \mu \mathrm{l}$ (for modern) or $25 \mu \mathrm{l}$ (for historical samples) total volumes. Reactions consisted of $1 \times$ colorless GoTaq Flexi buffer (Promega, Madison, WI, USA) or PCR Gold Buffer (Applied Biosystems (ABI), Carlsbad, CA, USA), 2.0-4.0 mM $\mathrm{MgCl}_{2}, 0.2 \mathrm{~mm}$ each dNTP, $1.2 \mathrm{mg} \mathrm{ml}^{-1}$ bovine serum albumin, $0.5 \mu \mathrm{m}$ each primer, 1 unit of Promega GoTaq Flexi or AmpliTaq Gold DNA polymerase and 1-3 $\mu$ l DNA extract. Thermocycle profiles consisted of a denaturation step of either $95^{\circ} \mathrm{C}$ for $2 \mathrm{~min}$ (for GoTaq Flexi) or $94^{\circ} \mathrm{C}$ for $8 \mathrm{~min}$ (for AmpliTaq Gold), followed by $35-45$ cycles of $95^{\circ} \mathrm{C}$ for $30 \mathrm{~s}$, a primer-specific annealing temperature for $30 \mathrm{~s}, 72{ }^{\circ} \mathrm{C}$ for $30-45 \mathrm{~s}$, proportional to the length of the fragment, and a final $72{ }^{\circ} \mathrm{C}$ extension step for either $7 \mathrm{~min}$ for sequences or $30 \mathrm{~min}$ for microsatellites. For sequencing, PCR products were cleaned up using a 1:10 dilution of ExoSAP-IT (USB, Cleveland, OH, USA), cycle-sequenced in both directions using the Big Dye Terminator v3.1 Cycle-Sequencing kit (ABI), and then purified through Sephadex G-50 fine columns (GE Healthcare Bio-Sciences, Piscataway, NJ, USA). All fragments were electrophoresed on an ABI 3130xL Genetic Analyzer. Sequences were assembled, aligned and visually inspected in SEQUENCHER v 4.9, and genotypes were assigned manually in GENEMAPPER v 4.1.

\section{Data analyses}

Prior to any analyses, the program GeneCAP (Wilberg and Dreher, 2004) was used to identify any individuals that may have inadvertently been sampled multiple times (for example, individuals banded during rehabilitation and later depredated in the breeding colony). The probability of identity (Sib P[ID]) was calculated from modern microsatellite genotypes and three duplicated individuals were identified $((P<0.05)$ : one individual from Maui and two from Kauai). In each case, the bird was sampled first as a chick or rehabilitated fledgling, and then later as a carcass (for example, a set of wings and tail or a cluster of feathers) collected on the same island.

\section{Sequences}

Mitochondrial DNA sequences were investigated to determine whether they could represent a nuclear copy. Sequences were characterized using MacClade v 4.08 (Maddison and Maddison, 2008) and translated in DambE v 5.1.2 (Xia and Xie, 2001). To visualize relationships among haplotypes at the population level, a statistical parsimony network for Cytochrome $b$ sequences was constructed using TCS v. 1.21 (Clement et al., 2000) with a 95\% connection limit. For both mitochondrial and nuclear sequence data sets, pairwise $\mathrm{F}_{\mathrm{ST}}$ was calculated in ARLEQUIN v 3.1 (Excoffier et al., 2005) from a Kimura two parameter distance matrix. This substitution model was selected using JModel Test (Posada, 2008) and the Akaike information criterion. Statistical significance of $\mathrm{F}_{\mathrm{ST}}$ values was determined through 1000 permutations. Two methods were used to correct for multiple tests: the sequential Bonferroni method (Rice, 1989) and the Benjamini-Hochberg false discovery rate (Benjamini and Hochberg, 1995). Both were found to yield the same results. ARLEQUIN was also used to determine whether there was a correlation between geographic and genetic distances. For all data sets, Mantel tests were conducted using Slatkin's linearized $\mathrm{F}_{\mathrm{ST}}$ and a matrix of distances between each of the islands, with significance determined through 1000 permutations.

We also used the coalescent-based program Migrate v 3.2.6 (Beerli and Felsenstein, 2001; Beerli, 2006) to estimate migration rates between islands. We used the Bayesian mode with uniform priors and substitution model parameters set to values estimated in JMODELTEST: the transition/transversion ratio $=14.0$ for mitochondrial data and 15.0, 3.0, 8.0 for the nuclear introns Enol, Lam and RP40, respectively, with rate heterogeneity for the mitochondrial locus modeled by a gamma distribution with $\alpha=0.083$. Three simultaneous replicate analyses were run with a single long chain of 20 million steps, of which the first $10 \%$ were discarded as burn-in. A static heating scheme with four chains was used to increase searching effectiveness, and heating parameters were set to 1.0, 1.2, 3.0 and 6.0. Convergence was assessed through examination of results from independent runs, and the effective sample sizes for all parameters were $\geqslant 1000$. Effective population size $(\theta)$ and gene flow $(m)$ estimates from MigRATE are compounded by the mutation rate (that is, $\theta=x \mathrm{Ne} \mu$ and $m=M / \mu$, where $x$ is a scalar dependent on the ploidy and inheritance mode of the locus). Therefore, to avoid making an assumption about mutation rates (particularly for the microsatellite data set), the effective number of migrants per generation $(\mathrm{NeM} / x)$ was calculated.

\section{Microsatellites}

The microsatellite data were screened for the presence of large-allele dropout and null alleles using the program Microchecker v. 2.2.3 (van Oosterhout et al., 2004). Null alleles are genotyping artifacts resulting from the differential amplification success of alleles (for example, due to genetic variability in priming sites) and can lead to an apparent excess of homozygotes. However, inbreeding, which can be an important issue for insular populations of endemic species (Frankham, 1998), results in the same pattern. If null alleles are present in the data set in high frequencies, they can bias estimates of population differentiation, such as $\mathrm{F}_{\mathrm{ST}}$. Therefore, we used the program INEsT (Chybicki and Burczyk, 2009) to simultaneously estimate the inbreeding coefficient and null allele frequency. The data were also checked for departure from Hardy-Weinberg expectations and the presence of gametic disequilibrium using the program GENEPOP v 4.0 (Rousset, 2008). The program ConverT (Glaubitz, 2004) was used to create infiles for further population genetic analyses. Simulations were conducted in Powsim (Ryman and Palm, 2006) to determine whether the microsatellite data set contained sufficient power to detect low levels of population genetic differentiation. In the simulated data sets, the effective population size was set to 1000 and divergence time to 10 , so that the overall $\mathrm{F}_{\mathrm{ST}}$ of the simulated populations was 0.005 . A total of 100 simulations were performed, with sample sizes from the simulated populations drawn corresponding to those utilized here, and significance determined through Fisher's exact test.

To investigate the levels of differentiation between Hawaiian petrels breeding on different islands, we calculated an estimate of $F_{S T}, G_{S T}^{\prime}$ and D for the microsatellite data set. $\mathrm{F}_{\mathrm{ST}}$ was originally derived for biallelic data and depends on the variation of the loci used. In the case of highly polymorphic markers, such as microsatellites, $\mathrm{F}_{\mathrm{ST}}$ may therefore underestimate genetic differentiation (Meirmans and Hedrick, 2011). Several alternative measures have been suggested, including $\mathrm{G}_{\mathrm{ST}}^{\prime}$ and $\mathrm{D}$. Both of these correct for maximum possible differentiation (Hedrick, 2005; Jost, 2008), but differ according to the aspect of genetic diversity examined: $\mathrm{G}_{\mathrm{ST}}^{\prime}$ examines heterozygosity, whereas D takes into account the effective number of alleles (Meirmans and Hedrick, 2011). An estimate of D was calculated using the package DEMETICs (Gerlach et al., 2010) implemented in R (R Development Core Team, 2009), and $\mathrm{G}_{\mathrm{ST}}^{\prime}$ was calculated using DEMEtics and the program RecodeData (Meirmans, 2006), where $\mathrm{G}_{\mathrm{ST}}^{\prime}=\mathrm{G}_{\mathrm{ST}} / \mathrm{G}_{\mathrm{ST}(\max )}$ (Meirmans and Hedrick, 2011). The unbiased estimator was used for both statistics, and $P$-values were determined using 1000 bootstrap replicates (Gerlach et al., 2010). Correction for multiple tests was conducted as indicated above. Gene flow was also estimated using the program Migrate, as described above, except that the Brownian motion approximation of the stepwise substitution model was used instead. 
The number of genetic populations was investigated using the Bayesian clustering program Structure v. 2.3.3 (Pritchard et al., 2000; Falush et al., 2003). This program uses multilocus genotypes to build genetic clusters that are in Hardy-Weinberg and linkage equilibrium. We conducted analyses for 1-8 genetic clusters $(K)$ using the admixture ancestry and the correlated allele frequency models, with sampling location information included as part of the prior (Hubisz et al., 2009). The model including sampling location information has been found to be sensitive to weak population structure, but unbiased when no structure exists. Eight independent replicates were performed, and runs were conducted for three million generations with the first 10\% discarded as burn-in. Results from Structure were input into the program STRUCTURE HARVESTER (Earl and vonHoldt, 2011), to calculate the ad-hoc $\Delta K$ statistic suggested by Evanno et al. (2005), which takes into account the change in the log probability of the data between increasing numbers of clusters.

\section{RESULTS}

\section{Mitochondrial sequences}

Mitochondrial DNA sequences were obtained for a total of 322 modern and historical Hawaiian petrel samples (Table 1). Sequences were deposited in the GenBank database under accession numbers HQ420351-HQ420378 and JN015638-JN015862. DNA was successfully amplified from $100 \%$ of the historical samples from Molokai, with a mean combined sequence length of $479 \mathrm{bp}$. There were no gaps present in the alignment, and after translation no nonsense or stop codons were found. Six amino-acid substitutions were detected: three were valine/methionine, and there was one each of tyrosine/histidine, alanine/threonine and asparagine/aspartic acid, although the last two substitutions occurred at very low frequency in the data set. The majority $(\sim 72 \%)$ of substitutions occurred in the third codon position, and 34 out of 35 were transitions. This evidence indicates that a nuclear origin of the sequences is unlikely. A total of 35 haplotypes were found with 11, 16, 7, 9 and 9 haplotypes from Hawaii, Maui, Lanai, Molokai and Kauai, respectively. In the statistical parsimony network (Figure 2), haplotypes tended to cluster according to island of origin. While a few common haplotypes were shared between islands, they occurred at different frequencies on each. In addition, each island had its own set of private haplotypes that did not occur on any of the other islands.

Overall, mitochondrial DNA sequences revealed significant differentiation among petrels breeding on different islands (global $\left.\mathrm{F}_{\mathrm{ST}}=0.425, P<0.001\right)$. Pairwise $\mathrm{F}_{\mathrm{ST}}$ values ranged between 0.037 and 0.633 (Table 2) and were significant in all comparisons involving contemporary populations. The highest $\mathrm{F}_{\mathrm{ST}}$ occurred between the islands of Lanai and Kauai $\left(\mathrm{F}_{\mathrm{ST}}=0.633\right)$, but differentiation was also high between Maui and Lanai $\left(\mathrm{F}_{\mathrm{ST}}=0.543\right)$. However, $\mathrm{F}_{\mathrm{ST}}$ was not significantly different from zero between birds from Lanai and the historic birds from Molokai. Mantel tests indicated that there was no significant relationship between genetic and geographic distance $(P=0.15)$. Results from Migrate concurred with estimates of $\mathrm{F}_{\mathrm{ST}}$, showing low migration between all pairs of populations. Posterior distributions for all analyses were unimodal and narrow, and all analyses showed that migration rates were very low. The highest migration estimate obtained was 0.004 migrants per generation, but the average migration rate was $\sim 0.002$ migrants per generation (Supplementary Table 3). For 13 out of 20 migration parameters, the $95 \%$ confidence interval included a migration rate of zero.

\section{Nuclear intron sequences}

Three nuclear introns were sequenced for each of 164 individuals, for a combined total of $741 \mathrm{bp}$ (Table 1). Sequences were deposited in the GenBank database under accession numbers HQ420460-HQ420515, HQ420604-HQ420659, HQ420746-HQ420801 and JN015863-JN016231.

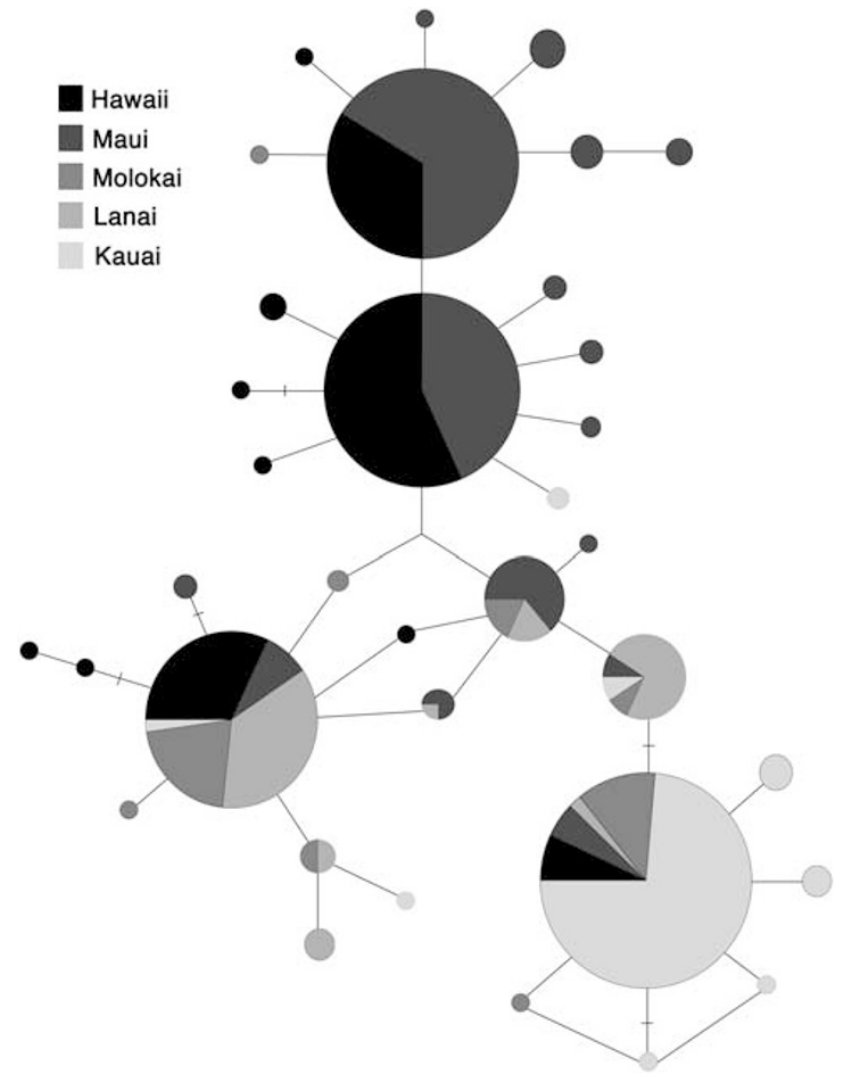

Figure 2 Haplotype network for modern and historic Hawaiian petrel mitochondrial Cytochrome $b$ sequences. The sizes of the circles are proportional to the haplotype frequency. All haplotypes differ by a single substitution, unless otherwise indicated by a hash mark, which represents the number of additional substitutions.

Table 2 Population differentiation of historic and modern Hawaiian petrels based on mitochondrial and nuclear intron data sets

\begin{tabular}{lccccc}
\hline & Hawaii & Maui & Lanai & Molokai & Kauai \\
\hline Hawaii & - & $0.092^{\mathrm{a}}$ & 0.060 & $\mathrm{NA}$ & $0.064^{\mathrm{a}}$ \\
Maui & $0.068^{\mathrm{a}}$ & - & $0.095^{\mathrm{a}}$ & $\mathrm{NA}$ & -0.030 \\
Lanai & $0.405^{\mathrm{a}}$ & $0.543^{\mathrm{a}}$ & - & $\mathrm{NA}$ & $0.145^{\mathrm{a}}$ \\
Molokai & $0.226^{\mathrm{a}}$ & $0.404^{\mathrm{a}}$ & 0.037 & - & $\mathrm{NA}$ \\
Kauai & $0.511^{\mathrm{a}}$ & $0.574^{\mathrm{a}}$ & $0.633^{\mathrm{a}}$ & $0.424^{\mathrm{a}}$ & - \\
\hline
\end{tabular}

Abbreviation: NA, not available.

Pairwise $\mathrm{F}_{\mathrm{ST}}$ values for the Cytochrome $b$ gene are below the diagonal, whereas those for a data set of sequences from three nuclear introns are above.

a Indicates the estimate is significantly different from zero after correction for multiple tests.

Sufficient nuclear data could not be obtained for historical Molokai samples, and so they were not included in further analyses. Sixteen variable sites were discovered in the remaining four populations, and of these fourteen were transitions and two were transversions. A total of 24 haplotypes were found: 3 for the Enol locus, 8 for Lam and 13 for RP40.

Nuclear sequences revealed a slightly different pattern of differentiation than that obtained from mitochondrial sequences. Overall, significant differentiation was found (global $\mathrm{F}_{\mathrm{ST}}=0.066, P<0.001$ ), with $\mathrm{F}_{\mathrm{ST}}$ for pairwise comparisons ranging from -0.030 to 0.145 (Table 2). One of the highest pairwise $\mathrm{F}_{\mathrm{ST}}$ values occurred between Maui and Lanai; however, there was no significant differentiation 
between birds from Hawaii and Lanai or between Maui and Kauai. Mantel tests suggested that there was no relationship between genetic isolation and geographic distance $(P=0.76)$. Results from Migrate indicated migration rates of 0.467 to over 10 migrants per generation (Supplementary Table 4). For seven of the twelve migration estimates, the $95 \%$ confidence intervals overlapped with zero, but all intervals also contained rates greater than 2 migrants per generation.

\section{Microsatellite data set}

A total of 232 individuals were genotyped for 18 microsatellite loci and there was an average of 6.7 alleles per locus (Supplementary Table 5). Expected heterozygosity ranged from 0.08 to 0.88 , with an average expected heterozygosity for each population between 0.57 and 0.62. Results from MicROCHECKER indicated that no locus exhibited large-allele dropout, but two loci (Ptero06 and Ptero10) did display evidence for the presence of null alleles. Examination of observed and expected heterozygosities also indicated an excess of homozygotes. Simultaneous estimation of the inbreeding coefficient and the null allele frequency from INEST indicated that inbreeding was low and that null allele frequencies ranged from 0.115 to 0.247 per population for Ptero06, and from 0.125 to 0.252 for Ptero10. The Ptero10 locus was previously found to contain a 38-bp deletion in some individuals (Welch and Fleischer, 2011), and additional undetected insertions or deletions could explain the relatively high incidence of null alleles. Primers could not be redesigned for this locus because sufficient flanking region was lacking. The cause of the observed excess of homozygotes for the Ptero06 locus remains unclear. Regardless, both loci were discarded from further analyses. No other loci deviated from Hardy-Weinberg equilibrium after correction for multiple tests. Two loci (Parm01 and RBG29) were found to be in linkage disequilibrium after correction for multiple tests, therefore the Parm01 locus was also discarded and a total of 15 loci were used in further analyses. These data are deposited in the Dryad repository at http://dx.doi.org/ 10.5061/dryad.1rk18128. Despite the removal of three loci, simulations demonstrated that the microsatellite data set still contained sufficient power to detect very weak population structure. Population structure was detected with $100 \%$ accuracy for simulated populations with an $\mathrm{F}_{\mathrm{ST}}$ of 0.005 . Even when $\mathrm{F}_{\mathrm{ST}}$ was decreased to 0.0025 , structure was correctly detected in $93 \%$ of simulations.

The microsatellite data set revealed patterns of differentiation similar to those of the mitochondrial data set. Overall, statistically significant differentiation was found (global $\mathrm{F}_{\mathrm{ST}}=0.019, P<0.001$ ). The highest values of $\mathrm{F}_{\mathrm{ST}}$ occurred between Lanai and Maui (Table 3). Estimates of $\mathrm{G}_{\mathrm{ST}}^{\prime}$ ranged from 0.015 to 0.057 , and estimates of $\mathrm{D}$ ranged from 0.022 to 0.060 . Both were higher than $\mathrm{F}_{\mathrm{ST}}$, as expected (Table 3), and all were significant after correction for multiple tests. Again, mantel tests showed no significant relationship between genetic and geographic distance $(P=0.94)$. Point estimates of migration rates

Table 3 Population differentiation for the microsatellite data set in modern Hawaiian petrels

\begin{tabular}{lcccc}
\hline & Hawaii & Maui & Lanai & Kauai \\
\hline Hawaii & - & $0.028^{\mathrm{a}}$ & $0.030^{\mathrm{a}}$ & $0.021^{\mathrm{a}}$ \\
Maui & $0.016^{\mathrm{a}}$ & - & $0.057^{\mathrm{a}}$ & $0.015^{\mathrm{a}}$ \\
Lanai & $0.021^{\mathrm{a}}$ & $0.033^{\mathrm{a}}$ & - & $0.046^{\mathrm{a}}$ \\
Kauai & $0.010^{\mathrm{a}}$ & $0.012^{\mathrm{a}}$ & $0.027^{\mathrm{a}}$ & - \\
\hline
\end{tabular}

Pairwise $\mathrm{F}_{\mathrm{ST}}$ is shown below the diagonal and $\mathrm{G}_{\mathrm{ST}}^{\prime}$ is shown above.

andicates the estimate is significantly different from zero after correction for multiple tests. from the program MigRATE ranged from 0.001 to about 8 migrants per generation (Supplementary Table 6). Overall, 95\% confidence intervals were broad and ranged from 0 to about 5 migrants per generation for most parameters.

Population structure was also investigated using a Bayesian clustering analysis. Initial runs with all individuals included in the analysis and the number of clusters $(K)$ set to 2 grouped individuals from Hawaii and Lanai separately from individuals on Maui (Figure 3), similar to the pattern suggested by the nuclear intron data set. Kauai birds appeared to be an admixture of the two groups. With $K=3$, Hawaii and Lanai remained grouped together, but Kauai was separated from that group as well as from Maui. Finally, with $K=4$, birds from each island formed separate groups, but individuals from Hawaii still contained some admixture with the Lanai population. Under the criteria of Evanno et al. (2005), the grouping $K=2$ received the greatest support (Supplementary Figure 1 ) as $\Delta K$ decreases substantially and tends to level off for values beyond this. Even though it is not possible to assess the level of support for the situation where $K=1$ using the Evanno criteria, the log probability of the data under this model was much lower (109 units) compared with models where $K=2$ and above. Further, posterior probability was highest for $K=2$, and effectively zero for $K=1$. While $K=4$ also did not receive strong support under the Evanno criteria in this initial analysis, it had the second highest log probability, which was just 19 likelihood units smaller than $K=2$.

As the Evanno method has been found to underestimate the number of genetic clusters present when population structure is weak (Waples and Gaggiotti, 2006), we conducted further analyses by dividing the data set as suggested by the initial results for $K=2$ and analyzing these groups separately. In the analysis that included Hawaii, Lanai and Kauai, the Evanno method gave high support for $K=3$ (Supplementary Figure 2), and for the analysis including Maui and Kauai, it gave high support for $K=2$ (Supplementary Figure 3). Investigation of the posterior probabilities concurred. Therefore, overall the STRUCTURE analyses support the presence of a genetic cluster corresponding to each island, similar to the $\mathrm{F}_{\mathrm{ST}}$ results.

\section{DISCUSSION}

We conducted a population genetic study of the endangered Hawaiian petrel using three data sets: sequences of the mitochondrial Cytochrome $b$ gene, sequences of three nuclear intron loci and
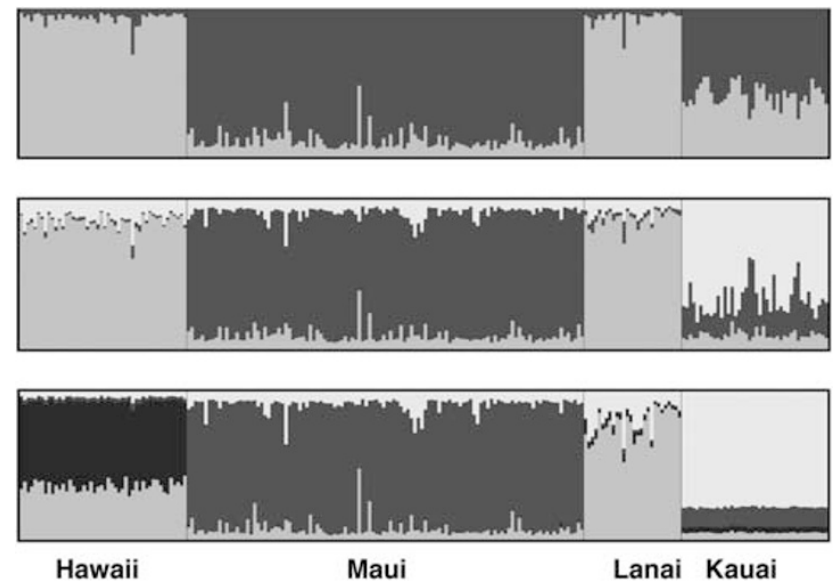

Figure 3 Genetic ancestry of Hawaiian petrels as estimated by the program STRUCTURE from the microsatellite data set using the admixed model with correlated allele frequencies and sampling location as a prior. Top $K$ (the number of genetic clusters) $=2$, middle $K=3$ and bottom $K=4$. 
genotypes from 15 microsatellite loci (data from three microsatellite loci were discarded). Analyses of these data revealed significant population genetic structure among all four modern populations. Contrary to expectations, differentiation was found even at very short distances between adjacent islands. In addition, significant differentiation was found between museum specimens collected from the potentially extirpated colony on Molokai and contemporary birds breeding on all islands except for those on Lanai.

\section{Contemporary population differentiation}

Consistent with the findings of Welch et al. (2011), the more extensive analysis conducted here on multiple data sets shows support for genetic isolation between modern populations of the Hawaiian petrel. Analyses of the mitochondrial DNA and microsatellite data sets showed significant differentiation between all contemporary population pairs. Similarly, nuclear intron results also showed significant isolation between most populations. Finally, a Bayesian clustering analyses performed using the program STRUCTURE indicated the presence of four genetic populations. Although sampling location was included as prior information in this analysis, which results in increased sensitivity (Hubisz et al., 2009), this model has not been found to be biased in cases where population structure is absent (Hubisz et al., 2009). Also, as mentioned above, the presence of population differentiation found in the STRUCtURE analysis is corroborated by other data sets and analyses. For the nuclear intron and microsatellite data sets, some of the highest pairwise $\mathrm{F}_{\mathrm{ST}}$ values were found between birds sampled on the adjacent islands of Maui and Lanai, which are separated by just $\sim 75 \mathrm{~km}$. The highest pairwise $\mathrm{F}_{\mathrm{ST}}$ in the mitochondrial data set occurred between Lanai and Kauai, which are $\sim 300 \mathrm{~km}$ apart. This is a very small distance when taking into account the fact that Hawaiian petrels are capable of, and in fact often make, foraging trips $>10000 \mathrm{~km}$ (Adams and Flora, 2010).

Overall, the signal of differentiation among populations appears to be stronger in the mitochondrial data set than in the nuclear data set. From mitochondrial DNA sequences the average pairwise $\mathrm{F}_{\mathrm{ST}}$ was 0.53 . However, the average $\mathrm{G}_{\mathrm{ST}}^{\prime}$ calculated from the microsatellite data (which corrects for higher levels of variability and also ranges from 0 to 1 ; Hedrick, 2005) was 0.033 . The mitochondrial levels of differentiation appear to be much closer to their theoretical maximum than do levels observed in the microsatellite data set. This is also demonstrated in the MigRATE analyses, where the average migration rate was 0.002 for the mitochondrial data set, but was $>0.780$ for the nuclear intron and microsatellite data sets. This is not likely to be related to low power in the microsatellite data set, as simulations demonstrated that extremely weak population genetic structure (for example, an $\mathrm{F}_{\mathrm{ST}}$ of 0.005 ) could be accurately detected in $100 \%$ of the tests. Instead, the pattern observed here could also be due to low levels of male-biased dispersal, which has been documented in some seabirds (Burg and Croxall, 2001). It could also be explained by recent divergence, which may be the case for the Hawaiian petrel (Welch et al., 2011). Without information from banding studies, it will be difficult to disentangle the genetic signatures of low levels of male-biased gene flow and incomplete lineage sorting. However, even if the strength of the signal is somewhat different, both mitochondrial and microsatellite data sets support the presence of four genetic populations within the Hawaiian petrel.

\section{Potential isolating mechanisms}

Population genetic structure has been documented in other procellariid seabird species. In the closely related Galapagos petrel an endangered, endemic species that is only known to breed on five islands, microsatellite data indicated the presence of four distinct populations.
The fifth population was suggested to be the result of a recent colonization (Friesen et al., 2006). Strong natal philopatry was proposed as an important mechanism promoting isolation between populations. In band-rumped storm petrels (Oceanodroma castro), populations from the Atlantic and Pacific Oceans showed high levels of divergence, likely due to separation by continental landmasses, but even within the same ocean basin populations showed some evidence of differentiation (Smith et al., 2007). However, population genetic structure has also been found to be lacking in many species, such as the gray-headed albatross (Thalassarche chrysostoma), and the white-capped albatross (T. steadi), even though differentiation was found in closely related species (Burg and Croxall, 2001; Abbott and Double, 2003). Thus, it is not easy to predict the presence of population genetic structure a priori in procellariiform seabirds, and further investigations of the mechanisms of isolation are necessary.

Geographic barriers are not likely factors in promoting divergence among Hawaiian petrel populations. Hawaiian petrel colonies are located in the same ocean basin, and are at most $\sim 500 \mathrm{~km}$ apart, so there are no obvious physical barriers to dispersal in this species. Patterns of differentiation could be linked to distance (Burg et al., 2003), however, this does not appear to be the case for Hawaiian petrels either. Mantel tests failed to find a relationship between genetic and geographic distance. In addition, populations on the adjacent islands of Maui and Lanai, which are just $\sim 75 \mathrm{~km}$ apart, show evidence of significant genetic isolation. In the Hawaiian archipelago, island age has been found to be related to genetic isolation for some species (Fleischer et al., 1998). However, Hawaiian petrels split from Galapagos petrels $\sim 550000$ years ago (Welch et al., 2011), and by that time all of the high islands present today had been formed. Finally, wind patterns can be an important factor in the flight of seabirds (Spear and Ainley, 1997) and could affect dispersal. Given the prevailing easterly trade winds in Hawaii, there is no evidence that wind direction or speed differ substantially between islands in a manner consistent with the patterns observed here, although further study would be beneficial.

Habitat characteristics could also influence levels of migration. Hawaiian petrels at present use two general types of breeding habitat: colonies on Maui and Hawaii both occur at high elevation sites with little precipitation and scrubby vegetation (Brandt et al., 1995; Hu et al., 2001), whereas the habitat on the islands of Lanai, Kauai and Molokai consists of lower elevation wet forest (Ainley et al., 1997). Birds may be reluctant to disperse between these different types of habitat. However, habitat type does not appear to be the only explanation for the observed patterns, because significant differentiation was found even between colonies occurring in similar habitat (for example, Lanai and Kauai). Habitat quality at the colony may also influence seabird dispersal, particularly if quality declines due to competition for nesting sites or other density-dependent factors (Inchausti and Weimerskirch, 2002; Kildaw, 2005). The Hawaiian petrel has been declining in abundance since the arrival of humans in the archipelago, so there may be little competition for nest sites and therefore reduced drive for contemporary dispersal (Schreiber and Burger, 2002; Pyle and Pyle, 2009).

Friesen et al. (2007a) suggested that population-specific foraging ranges, particularly in the nonbreeding season, may act to reduce gene flow. If birds spend the nonbreeding season in population-specific areas, then they may return together to the same breeding colony (Burg and Croxall, 2001). Pair formation and copulation are both thought to occur primarily on the breeding grounds for the Hawaiian petrel (Simons, 1985; Warham, 1990), and therefore 
population-specific foraging or nonbreeding distributions could lead to population differentiation. Wiley et al. (2012, in preparation), examined the stable isotope composition of primary feathers, which are grown during the nonbreeding season, and found populationspecific signatures. Adults from Hawaii and Lanai had a very similar stable carbon and nitrogen isotope composition (congruent with STRUCTURE results with $K=2$ and 3), whereas individuals from Maui and Kauai both differed significantly from them in nitrogen isotope values, likely due to differences in foraging location. This could be one mechanism leading to population isolation in the Hawaiian petrel.

Strong natal philopatry could also lead to population differentiation (Friesen et al., 2007a). Banding studies suggest that, in general, procellariiform seabirds are highly philopatric (Warham, 1990). This mechanism is often invoked when population structure is found in species for which banding information is lacking and there are no other obvious factors preventing dispersal (Friesen et al., 2007a). Natal philopatry followed by drift could explain the genetic differentiation found between populations of the Hawaiian petrel. It could also explain recently documented biological differences between populations. For example, vocalizations of Hawaiian petrels were found to be unique on each island (Judge, 2011). Little is known about how procellariiform seabirds acquire their calls, but in some petrel species it may be innate: a snow petrel chick (Pagodroma nivea) raised by another species developed snow petrel vocalizations (Bretagnolle, 1996). Differences in call may have developed due to drift in isolated populations. Judge (2011) also found that adults from Maui were significantly larger than adults from Hawaii and Kauai, in both wing chord and tarsus length, and that birds on Maui breed about 30 days earlier than birds on all of the other islands. Taken together, all of these factors may work together to minimize contemporary gene flow.

\section{Population extirpation and gene flow}

Investigation of a presumably extirpated population on the island of Molokai revealed significant differentiation from all of the modern populations except for the adjacent island of Lanai. By the early 1900s, the number of Hawaiian petrels breeding on Molokai had apparently already begun declining, likely due to the introduction of mongoose as well as habitat degradation by introduced feral ungulates (Bryan, 1908). During the same time period, habitat conditions for petrels on Lanai were probably also less than ideal due to grazing by ungulates, which led to severe habitat degradation as early as 1870 . Continued foraging impeded natural recovery until 1911 when goats were removed from the island (Munro, 2007) and forest restoration began. While petrels may not have ever been completely extirpated from Lanai, the recent discovery of a large breeding colony there (Birdlife International, 2011), just a handful of generations later, is somewhat unexpected given that these long-lived petrels lay a single egg each year and exhibit delayed maturity. Findings of significant population structure among extant populations, and failure of biologists to relocate formerly large colonies on Molokai, coupled with no significant divergence between birds from Molokai and Lanai, may indicate that petrels from Molokai were displaced to Lanai as the Molokai colony dwindled due to anthropogenic influences. It is also possible that a recent colonization event occurred on these islands or that there was a substantial level of gene flow between them prior to the decline of the Molokai population.

Several lines of evidence indicate that displacement of Hawaiian petrels from Molokai to Lanai could be possible. The islands of Molokai and Lanai are separated by just $\sim 30 \mathrm{~km}$, exhibit peaks of similar elevations and have similar habitats (Wagner et al., 1999), which could have facilitated movement between colonies on these islands. In addition, social attraction has been found to be important for many seabirds (Parker et al., 2007) and therefore individuals, particularly young birds prospecting for nest sites, may preferentially disperse away from dwindling colonies. There is also evidence that seabirds may disperse from colonies in response to declining conditions, and that dispersal can be substantial in some cases. Kildaw (2005) found that seabirds, including previously established breeders, dispersed in response to poor habitat quality and reduced reproductive success. Similarly, Oro and Ruxton (2001) demonstrated largescale dispersal to a newly formed seabird colony. However, these examples arise from charadriiform seabirds and may not translate directly to procellariiform seabirds. Within this order, Black-browed albatrosses have recently been confirmed to be breeding on several islands in the south-west Pacific, despite their apparent absence there early in the twentieth century, providing evidence that procellariiform seabirds do indeed disperse from natal colonies (Moore et al., 2001). Wandering albatrosses (Diomedea exulans) are known to disperse when population density at the colony is high (Inchausti and Weimerskirch, 2002), and accordingly no evidence for population structure has been found in this species (Burg and Croxall, 2004; Milot et al., 2008). Unfortunately the densities of Hawaiian petrel populations on Lanai and Molokai prior to human contact remain unknown. Therefore, while levels of dispersal between the populations on Lanai and Molokai may have consistently been large in the past, it is also possible that petrels from Molokai were displaced to Lanai as that colony became extirpated due to predation and habitat disturbance.

If petrels are able to overcome isolating mechanisms and disperse prior to complete extirpation then this could explain why some species do not seem to exhibit population genetic differentiation, despite evidence of strong philopatry from mark-recapture studies. For example, the Laysan albatross is known to exhibit strong natal philopatry (Fisher, 1976), but very weak population structure was found in this species (Young, 2010). While density-dependent dispersal was suggested as one potential cause, displacement from several extirpated colonies could also lead to weak population structure. A pattern of dispersal due to displacement could also explain why seabird extinction is relatively rare in the Pacific despite the high prevalence of local population extirpation (Steadman, 1995).

\section{Conservation implications}

Resources for conservation management of endangered species are always limited, and therefore an understanding of population differentiation and connectivity can help identify conservation priorities and inform management decisions. For example, if populations were panmictic then it might be more beneficial to focus resources on large populations or those that are more easily managed instead of utilizing a disproportionately large amount of resources on conserving small, severely declining and remote populations. Here our results indicate that Hawaiian petrel populations on each island could be considered distinct management units (Fraser and Bernatchez, 2001) and targeted for conservation actions to prevent the loss of genetic diversity. Significant levels of differentiation indicate that each population contains some unique genetic variation and might be embarking on its own evolutionary trajectory. This is concordant with recent work indicating that some populations may also be ecologically distinct (Wiley et al., 2012). Practically, the strategy of managing each population separately is also necessary because management concerns are unique on each island. In addition to differences among interisland nesting habitats mentioned above, the number and types of predators differ (for example, cats, rats, mongooses, owls), as do the presence and magnitude of other anthropogenic threats, such as wind 
turbines, attraction to artificial light sources and collisions with power lines (Ainley et al., 1997; Cooper and Day, 1998; Hodges and Nagata, 2001; Carlile et al., 2003).

The colony on Mauna Loa, Hawaii warrants particular attention. This population appears to be declining at a faster rate than the others, and population viability analyses indicate that it could become extirpated in the near future ( $\mathrm{Hu}$ et al., 2001). At a minimum, more comprehensive measures to reduce predation within nesting areas are urgently needed if this population is to remain viable. This population may also benefit from translocations (Miskelly et al., 2009). One potential option is to move eggs or chicks from the relatively large colonies on Maui or Lanai to Hawaii. Populations from Lanai and Hawaii appear to be ecologically similar (Wiley et al., in preparation), but the demographic trend on Lanai remains unclear. The colony at Haleakala, Maui, is perhaps the largest colony of Hawaiian petrels and may be beginning to stabilize (Carlile et al., 2003). Although significant genetic differentiation was observed between all of these populations, those on Maui and Lanai also appear to be most genetically similar to the Hawaii population, and the levels of differentiation found are not to the extent where outbreeding depression would be a major issue (Frankham et al., 2011). Artificial gene flow would cause some genetic homogenization of the Hawaii population, but without it that population, and its unique genetic variation, may be lost completely from the species. In addition, admixture with another population, such as may have occurred between individuals from Molokai and Lanai, could be a natural response in these petrels. Such translocations would only be beneficial, however, if predation by introduced mammals could be effectively controlled or eliminated. If that is not possible, then translocating eggs or chicks away from the colony on Mauna Loa (and potentially also encouraging prospecting adults to move away as well) to another safer, more easily managed location could be a better option.

\section{CONCLUSION}

Here we demonstrate that populations of Hawaiian petrels, even those separated by as little as $75 \mathrm{~km}$, are genetically isolated from one another, potentially due to strong natal philopatry or populationspecific nonbreeding distributions. Many seabirds, especially endemic species, are increasingly threatened by extinction, and identifying isolated populations can be important for preserving genetic diversity and developing conservation management plans and priorities. This is true for enigmatic species, such as nocturnal, burrownesting seabirds like the Hawaiian petrel, but also for seabird species that are more well known, because distinct evolutionary lineages may go unnoticed (Hailer et al., 2011) and become extirpated without further investigation.

\section{DATA ARCHIVING}

Mitochondrial and nuclear intron sequence data have been deposited in the GenBank database under accession numbers HQ420351HQ420378, JN015638-JN015862, HQ420460-HQ420515, HQ420604HQ420659, HQ420746-HQ420801 and JN015863-JN016231. Microsatellite data have been deposited in the Dryad repository: http://dx.doi.org/10.5061/dryad.1rk18128.

\section{CONFLICT OF INTEREST}

The authors declare no conflict of interest.

\section{ACKNOWLEDGEMENTS}

We thank David Anderson, David Duffy, David Ainley and Seth Judge for access to samples and/or valuable discussion on petrel biology. We thank
Hawaii Volcanoes National Park for providing permission to sample salvaged petrel carcasses. For the permission and assistance in sampling museum specimens, we thank James Dean, Megan Spitzer and Christina Gebhard of the Bird Division at the Smithsonian Institution's National Museum of Natural History; Carla Kishinami and Lydia Garetano at the Bernice P Bishop Museum; and Kimball Garrett at the Los Angeles County Museum of Natural History. We thank Amy Wilson, Frank Hailer and Brandt Ryder for discussion on data analysis; Peter Pyle, Hannah Nevins and three anonymous reviewers for comments on earlier drafts, as well as Heather Lerner, Nancy Rotzel, Emily Latch and other members of the Center for Conservation and Evolutionary Genetics at the Smithsonian Institution's National Zoological Park. Funding for this study was provided by the Behavior, Ecology and Evolution Program at the University of Maryland, the Smithsonian Office of Fellowships, the Smithsonian's Walcott Fund, the Center for Conservation and Evolutionary Genetics and the National Science Foundation (grant \# DEB-0745604 to P Ostrom, $\mathrm{R}$ Fleischer and $\mathrm{H}$ James). Procedures for handling live birds were approved by the Western Ecological Research Center Animal Care and Use Committee (protocol 9370BQ9TSK1102) and the Smithsonian National Museum of Natural History Animal Care and Use Committee (protocol 200903). Samples were collected under the Endangered Species Act permit TE-145562 and the cooperative agreement between the Hawaii Department of Land and Natural Resources and the US Fish and Wildlife Service. The use of trade names in this study is for descriptive purposes only and does not imply endorsement by the US Government.

Abbott CL, Double MC (2003). Genetic structure, conservation genetics and evidence of speciation by range expansion in shy and white-capped albatrosses. Mol Ecol 12 : 2953-2962.

Abbott CL, Double MC, Trueman JW, Robinson A, Cockburn A (2005). An unusual source of apparent mitochondrial heteroplasmy: duplicate mitochondrial control regions in Thalassarche albatrosses. Mol Ecol 14: 3605-3613.

Adams J, Flora S (2010). Correlating seabird movements with ocean winds: linking satellite telemetry with ocean scatterometry. Marine Biol 157: 915-929.

Ainley DG, Podolsky R, Deforest L, Spencer G (1997). New insights into the status of the Hawaiian petrel on Kauai. Colonial Waterbirds 20: 24-30.

Allendorf FW, Luikart G (2007). Conservaton and the Genetics of Populations. Blackwell Publishing: Malden, MA.

Beerli P (2006). Comparison of Bayesian and maximumn-likelihood inference of population genetic parameters. Bioinformatics 22: 341-345.

Beerli P, Felsenstein J (2001). Maximum likelihood estimation of a migration matrix and effective population sizes in $\mathrm{n}$ subpopulations by using a coalescent approach. Proc Natl Acad Sci USA 98: 4563-4568.

Benjamini Y, Hochberg $Y$ (1995). Controlling the false discovery rate: a practical and powerful approach to multiple testing. J $R$ Stat Soc Series B 57: 289-300.

Birdlife International (2011). Species factsheet: Pterodroma sandwichensis. http://www. birdlife.org/datazone/speciesfactsheet.php?id=3896 (Accessed 1 February 2012).

Brandt CA, Parrish JK, Hodges CN (1995). Predictive approaches to habitat quantification: dark-rumped petrels on Haleakala, Maui. Auk 112: 571-579.

Bretagnolle V (1996). Acoustic communication in a group of non-passerine birds, the petrels. In: Kroodsma DE, Miller EH (eds). Ecology and Evolution of Acoustic Communication in Birds. Cornell University Press: Ithaca, NY, pp 160-177.

Browne RA, Anderson DJ, Houser JN, Cruz F, Glasgow KJ, Hodges CN et al. (1997). Genetic diversity and divergence of endangered Galapagos and Hawaiian Petrel populations. Condor 99: 812-815.

Bryan WA (1908). Some birds of Moloka'i. Bernice P Bishop Museum Occasional Papers 4 : 43-86.

Burg TM, Croxall JP (2001). Global relationship amongst black-browed and grey-headed albatrosses: analysis of population structure using mitochondrial DNA and microsatellites. $\mathrm{Mol}$ Ecol 10: 2647-2660.

Burg TM, Croxall JP (2004). Global population structure and taxonomy of the wandering albatross species complex. Mol Ecol 13: 2345-2355.

Burg TM, Lomax J, Almond R, Brooke MdL, Amos W (2003). Unravelling dispersal patterns in an expanding population of a highly mobile seabird, the norther fulmar (Fulmarus glacialis). Proc R Soc Lond B 270: 979-984.

Carlile N, Priddle D, Zino F, Natividad C, Wingate DB (2003). A review of four successful recovery programmes for threatened sub-tropical petrels. Marine Ornitho/ 31: 185-192.

Chybicki IJ, Burczyk J (2009). Simultaneous estimation of null alleles and inbreeding coefficients. J Heredity 100: 106-113.

Clement M, Posada D, Crandall K (2000). TCS: a computer program to estimate gene genealogies. Mol Ecol 9: 1657-1660.

Cooper BA, Day RH (1998). Summer behavior and mortality of dark-rumped Petrels and Newell's Shearwaters at power lines on Kauai. Colonial Waterbirds 21: 11-19.

Croll DA, Maron JL, Estes JA, Danner EM, Byrd GV (2005). Introduced predators transform subartic islands from grassland to tundra. Science 307: 1959-1961. 
Earl DA, vonHoldt BM (2011). Structure Harvester: a website and program for visualizing Structure output and implementing the Evanno method. Conservation Genetics Resources (in press, DOI:10.1007/s12686-011-9548-7).

Evanno G, Regnaut S, Goudet J (2005). Detecting the number of clusters of individuals using the software Structure: a simulation study. Mol Ecol 14: 2611-2620.

Excoffier L, Laval G, Schneider S (2005). Arlequin ver. 3.0: an integrated software package for population genetics data analysis. Evol Bioinform Online 1: 47-50.

Falush D, Stephens M, Pritchard JK (2003). Inference of population structure using multilocus genotype data: linked loci and correlated allele frequencies. Genetics 164 1567-1587.

Fisher HI (1976). Some dynamics of a breeding colony of Laysan Albatrosses. Wilson Bull 88: $121-142$.

Fleischer RC, McIntosh CE, Tarr CL (1998). Evolution on a volcanic conveyor belt: using phylogeographic reconstructions and K-Ar-based ages of the Hawaiian Islands to estimate molecular evolutionary rates. Mol Ecol 7: 533-545.

Fleischer RC, Olson SL, James HF, Cooper AC (2000). Identification of the extinct Hawaiian Eagle (Haliaeetus) by mtDNA sequence analysis. Auk 117: 1051-1056.

Frankham R (1998). Inbreeding and extinction: Island populations. Conservation Biol 12: 665-675.

Frankham R, Ballou JD, Briscoe DA (2002). Introduction to Conservation Genetics. Cambridge University Press: Cambridge, UK.

Frankham R, Ballou JD, Eldridge MD, Lacy RC, Ralls K, Dudash MR et al. (2011). Predicting the probability of outbreeding depression. Conservation Biol 25 465-475.

Fraser DJ, Bernatchez L (2001). Adaptive evolutionary conservation: towards a unified concept for defining conservation units. Mol Ecol 10: 2741-2752.

Friesen VL, Burg TM, McCoy KD (2007a). Mechanisms of population differentiation in seabirds. Mol Ecol 16: 1765-1785.

Friesen VL, Congdon BC, Kidd MG, Birt TP (1999). Polymerase chain reaction (PCR) primers for the amplification of five nuclear introns in vertebrates. Mol Ecol 8: 2147-2149.

Friesen VL, Congdon BC, Walsh HE, Birt TP (1997). Intron variation in marbled murrelets detected using analyses of single-stranded conformational polymorphisms. $\mathrm{Mol} \mathrm{Ecol} 6$ : 1047-1058

Friesen VL, González JA, Cruz-Delgado F (2006). Population genetic structure and conservation of the Galapagos petrel (Pterodroma phaeopygia). Conservation Genet 7: 105-115.

Friesen VL, Smith AL, Gomez-Diaz E, Bolton M, Furness RW, Gonzalez-Solis J et al. (2007b). Sympatric speciation by allochrony in a seabird. Proc Natl Acad Sci USA 104: 18589-18594.

Fukami T, Wardle DA, Bellingham PJ, Mulder CPH, Towns DR, Yeates GW et al. (2006). Above- and below-ground impacts of introduced predators in seabird-dominated island ecosystems. Ecol Lett 9: 1299-1307.

Gangloff B, Shirihai H, Watling D, Cruaud C, Couloux A, Tillier A et al. (2011). The complete phylogeny of Psuedobulweria, the most endangered seabird genus: systematics, species status and conservation implications. Conservation Genet 13: 39-52.

Gerlach G, Jeuterbock A, Kraemer P, Deppermann J, Harmand P (2010). Caculations of population differentiation based on Gst and D: forget Gst but not all of statistics!. Mol Ecol 19: 3845-3852.

Glaubitz JC (2004). Convert: a user-friendly program to reformat diploid genotypic data for commonly used population genetic software packages. Mol Ecol Notes 4 309-310.

Hailer F, Schreiber EA, Miller JM, Levin II, Parker PG, Chesser RT et al. (2011). Long-term isolation of a highly mobile seabird on the Galapagos. Proc $R$ Soc B: Biol Sci 278 817-825.

Hedrick PW (2005). A standardized genetic differentiation measure. Evolution 59: 1633-1638.

Hodges CN, Nagata RJS (2001). Effects of predator control on the survival and breeding success of the endangered Hawaiian dark-rumped petrel. In: Scott JM, Conant S, Van Riper Cl (eds). Studies in Avian Biology: Evolution, Ecology, Conservation, and Management of Hawaiian birds: A Vanishing Avifauna. Cooper Ornithological Society: Camarillo, CA, pp. 308-318.

Hu D, Glidden C, Lippert JS, Schnell L, Maclvor JS, Meisler J (2001). Habitat use and limiting factors in a population of Hawaiian dark-rumped petrels on Mauna Loa, Hawaii. In: Scott JM, Conant S, Van Riper Cl (eds). Studies in Avian Biology: Evolution, Ecology, Conservation and Management of Hawaiian Birds: a Vanishing Avifauna. Cooper Ornithological Society: Camarillo, CA, pp. 234-242.

Hubisz M, Falush D, Stephens M, Pritchard JK (2009). Inferring weak population structure with the assistance of sample group information. $\mathrm{Mol}$ Ecol Resources 9: 1322-1332.

Inchausti P, Weimerskirch H (2002). Dispersal and metapopulation dynamics of an oceanic seabird, the wandering albatross, and its consequences for its response to long-line fisheries. J Animal Ecol 71: 765-770.

Jost L (2008). Gst and its relatives do not measure differentiation. Mol Ecol 17 4015-4026

Judge S (2011). Interisland Comparison of Behavioral Traits and Morphology of the Endangered Hawaiian Petrel: Evidence for Character Differentiation. University of Hawaii: Hilo, Hawaii, USA

Kildaw SD (2005). Formation and growth of new seabird colonies: the significance of habitat quality. Marine Ornithol 33: 49-58.

Maddison DR, Maddison WP (2008). MacClade v 4.08. Sinauer Associations: Sunderland, MA

Meirmans $P$ (2006). Using the AMOVA framework to estimate a standardized genetic differentiation measure. Evolution 60: 2399-2402.
Meirmans P, Hedrick PW (2011). Assessing population structure: Fst and related measures. Mol Ecol Resources 11: 5-18.

Milot E, Weimerskirch H, Bernatchez L (2008). The seabird paradox: dispersal, genetic structure and population dynamics in a highly mobile, but philopatric albatross species. Mol Ecol 17: 1658-1673

Miskelly CM, Taylor GA, Gummer H, Williams R (2009). Translocations of eight species of burrow-nesting seabirds (genera Pterodroma, Pelecanoides, Pachyptila and Puffinus: Family Procellariidae). Biol Conservation 142: 1965-1980.

Moore PJ, Burg TM, Taylor GA, Millar CD (2001). Provenance and sex ratio of Black-browed Albatross, Thalassarche melanophrys, breeding on Campbell Island, New Zealand. Emu 101: 329-334.

Munro GC (1955). Hawaii's birds and their homes: how to save them from extinction. Part $\mathrm{XI}$-seabirds of the main group. Elepaio 16: 46-47.

Munro GC (2007). The story of Lana'i. Privately published by the Munro family, Lanai, Hawaii, USA.

Olson SL, James H (1982). Prodromus of the fossil avifauna of the Hawaiian Islands. Smithsonian Contributions to Zoology 365: 1-59.

Oro D, Ruxton GD (2001). The formation and growth of seabird colonies: Audouin's gull as a case study. J Animal Ecol 70: 527-535.

Parker MW, Kress SW, Golightly RT, Carter HR, Parsons EB, Schubel SE et al. (2007). Assessment of social atraction techniques used to restore a common murre colony in central California. Waterbirds 30: 17-28.

Podolsky R, Ainley DG, Spencer G, Deforest L, Nur N (1998). Mortality of Newell's Shearwaters caused by collisions with urban structures on Kauai. Colonial Waterbirds 21: $20-34$.

Posada D (2008). jModelTest: Phylogenetic model averaging. Mol Biol Evol 25: 1253-1256.

Pritchard JK, Stephens M, Donnelly P (2000). Inference of population structure using multilocus genotype data. Genetics 155: 945-959.

Pyle RL, Pyle P (2009). Hawaiian petrel. In: The Birds of the Hawaiian Islands: Occurrence, History, Distribution, and Status. B. P. Bishop Museum: Honolulu, HI. http://hbs.bishopmuseum.org/birds/rlp-monograph.

R Development Core Team (2009). R: A Language and Environment for Stasticial Computing. R Foundation for Statistical Computing: Vienna, Austria.

Rice WR (1989). Analyzing tables of statistical tests. Evolution 43: 223-225.

Rousset F (2008). GENEPOP'007: a complete re-implementation of the GENEPOP software for Windows and Linux. Mol Ecol Resources 8: 103-106.

Rozen S, Skaletsky HJ (2000). Primer3 on the WWW for general users and biologist programmers. In: Krawetz S, Misener S (eds). Bioinformatics Methods and Protocols: Methods in Molecular Biology. Humana Press: Totowa, NJ, pp. 365-386.

Ryman N, Palm S (2006). POWSIM: a computer program for assessing statistical power when testing for genetic differentiation. Mol Ecol Notes 6: 600-602.

Schreiber EA, Burger J (2002). Biology of Marine Birds. CRC Press: Boca Raton, FL.

Simons TR (1984). A population model of the endangered Hawaiian dark-rumped petrel. J Wildlife Management 48: 1065-1076.

Simons TR (1985). Biology and behavior of the endangered Hawaiian dark-rumped petrel. Condor 87: 229-245.

Simons TR, Hodges CN (1998). Dark-rumped petrel (Pterodroma phaeopygia). In: Poole A (ed). The Birds of North America Online. Cornell Lab of Ornithology:

Smith AL, Monteiro L, Hasegawa O, Friesen VL (2007). Global phylogeography of the bandrumped storm-petrel (Oceanodroma castro; Procellariiformes : Hydrobatidae). $\mathrm{Mol}$ Phylogenet Evol 43: 755-773.

Spear LB, Ainley DG (1997). Flight behavior of seabirds in relation to wind direction and wing morphology. Ibis 139: 221-233.

Spear LB, Ainley DG, Nur N, Howell SNG (1995). Population size and factors affecting at-sea distribution of four endangered Procellariids. The Codor 97: 613-638.

Steadman DW (1995). Island birds: biodiversity meets zooarchaeology. Science 267: 1123-1131.

Steeves TE, Anderson DJ, Friesen VL (2005). The Isthmus of Panama: a major physical barrier to gene flow in a highly mobile pantropical seabird. J Evol Biol 18: 1000-1008.

Taberlet P, Griffin S, Goosens B (1996). Reliable genotyping of samples with very low DNA quantities using PCR. Nucleic Acids Res 24: 3189-3194.

van Oosterhout C, Hutchinson WF, Wills DPM, Shipley P (2004). Micro-Checker: software for identifying and correcting genotyping errors in microsatellite data. Mol Ecol Notes 4: $535-538$.

Wagner WL, Herbst DR, Sohmer SH (1999). Manual of the flowering plants of Hawaii. University of Hawai'i Press and Bishop Museum Press: Honolulu, $\mathrm{HI}$.

Waples RS, Gaggiotti O (2006). What is a population? An empirical evaluation of some genetic methods for identifying the number of gene pools and their degree of connectivity. Mol Ecol 15: 1419-1439.

Warham J (1990). The Petrels: Their Ecology and Breeding Systems. Academic Press: New York.

Welch AJ, Fleischer RC (2011). Polymorphic microsatellite markers for the endangered Hawaiian petrel (Pterodroma sandwichensis). Conservation Genetics Resources 3: 581-584.

Welch AJ, Yoshida AA, Fleischer RC (2011). Mitochondrial and nuclear DNA sequences reveal recent divergence in morphologically indistiguishable petrels. $\mathrm{Mol}$ Ecol 20: $1364-1377$. 
Wilberg MJ, Dreher BP (2004). GENECAP: a program for analysis of multilocu genotype data for non-invasive sampling and capture-recapture population estimation. $\mathrm{Mol} E \mathrm{CO}$ Notes 4: 783-785.

Wiley $\mathrm{AE}$, Ostrom PH, James HF, Welch AJ, Fleischer RC, Gandhi $\mathrm{H}$ et al. (in preparation). A millenial-scale record of foraging ecology in the endangered Hawaiian petrel: Isotopic evidence of recent human impact to the pelagic food webs.
Wiley AE, Welch AJ, Ostrom PH, James HF, Stricker CA, Fleischer RC et al. (2012). Foraging segregation and genetic divergence between geographically proximate colonies of a highly mobile seabird. Oecologia 1: 119-130.

Xia X, Xie Z (2001). DAMBE: software package for data analysis in molecular biology and evolution. J Heredity 92: 371-373.

Young LC (2010). Inferring colonization history and dispersal patterns of a long-lived seabird by combining genetic and empirical data. J Zool 281: 232-240.

Supplementary Information accompanies the paper on Heredity website (http://www.nature.com/hdy) 